\title{
PULMONARY FUNCTIONS AND ITS CORRELATION WITH SERUM IRON LEVELS IN WOMEN AT THE THIRD TRIMESTER OF PREGNANCY
}

\author{
Ahed Najimeldin Abdullah ${ }^{*}$,HAZhmat Abdolkhaliq Ali,IHSAn ,Hussein Muhammed Ali* \\ AND SALIM AL-NAEMY ${ }^{* * * *}$ \\ * Dept. of Physiology, College of Dentistry, University of Duhok, Kurdistan region - Iraq. \\ ** Dept. of Physiology, College of Medicine, University of Duhok, Kurdistan region - Iraq. \\ *** Dept. of Physiology, College of Medicine, University of Duhok, Kurdistan region - Iraq.
}

(Received: April 18, 2019; Accepted for Publication: August 5, 2019)

\begin{abstract}
Background and Objectives: There is a series of physiological alterations that taken place during pregnancy as a result of gradual growth of the fetus. Among alterations that occur during pregnancy are changes in the lung volumes. In this study we aim to evaluate the pulmonary functions in pregnant women at the third trimester of pregnancy and to determine the correlation between pulmonary functions and serum iron levels.

Methods: Physical examination as well as case history and all requested information were taken by a questionnaire. Measurement of serum iron was done manually using commercial kit (Biolab, France). Pulmonary functions test was carried out using a computerized Spirometer device (ROME-Italy).

Results: FEV1, FVC and $\mathrm{O} 2$ saturation \% showed a decrease in study group (untreated) but were not statistically significant $(p=0.31,0.98$ and 0.14$)$ respectively. However, only FEV1/FVC displayed a statistically significant decline in study group compared to controls. Although there was an obvious positive correlation between serum iron and FEV1, FVC and FEV1/FVC, none of them showed a statistically significant correlation $(r=0.238,0.493$ and 0.969$)$ respectively.

Conclusion: Decline in lung volumes is correlated (although not significant) with low serum iron in pregnant women at the third trimester.
\end{abstract}

KEY WORDS: Pulmonary functions test, Iron deficiency anemia and Pregnancy.

\section{INTRODUCTION}

$\mathbf{T}$ There is a series of physiological, anatomical and biochemical alterations that taken place during pregnancy including all trimesters making. ${ }^{1}$ In pregnancy, the systems of the human's body develop adaptation towards these changes which occur as a result of gradual growth of the fetus. ${ }^{2}$ Among alterations that occur during pregnancy are changes in the physiology of the respiratory system particularly lung volumes. ${ }^{3}$ Previous research indicated that, changes in the lung volumes occur which result in pulmonary dysfunctions whereas others concluded that changes in the lung functions is a part of homeostasis process towards pregnancy. ${ }^{4}$ Although sufficient research highlighted the evaluation of pulmonary functions during pregnancy, very limited ones focused precisely on the third trimester. ${ }^{5}$

However, iron deficiency anemia which is one of the common conditions occurring in pregnancy particularly in the third trimester is well documented in previous studies ${ }^{6}$. In this study we aim to evaluate the pulmonary functions in pregnant women at the third trimester of pregnancy and to determine the correlation between pulmonary functions and serum iron levels.

\section{MATERIALS AND METHODS}

Upon approval by the research committee at Duhok College of Medicine, this case control study involved 120 participants representing both study and control group. All participants were recruited to Duhok Delivery Hospital who were regular visitors for routine clinical 
assessment for their pregnancies. Both study group individual's involved pregnant women at their third trimester of pregnancy but the only difference was that study group (untreated) did not take iron and folic acid supplements whereas control (treated) subject received $(400 \mu \mathrm{g} /$ day $)$. Physical examination of study group was done as well as case history and all necessary and relevant information were taken by a questionnaire including height, weight and body mass index. Upon their approval, five milliliters of venous blood was collected from each participant for necessary laboratory investigations.

Blood samples collected from study groups were previously put in EDTA tubes were used for hematological tests. Complete blood count (CBC) test for each sample was done using automated hematology analyzer (Colter machine). Measurement of serum iron was done manually using commercial kit (Biolab, France). Pulmonary functions test was carried out using Spirolap III device (a computerized Spirometer, 00155 ROME-Italy). Among many parameters, only the following parameters were used in this study; forced vital capacity (FVC), forced expiratory volume in one second (FEV1) and FEV1/FVC ratio in addition to the percentage of oxygen saturation. Patients were asked to take a rest for at least 15 minutes, then they were made to undergo pulmonary function test for three times at every 15 minutes interval. Mean of three measurements was taken into consideration.

Statistical package for social science (SPSS) version 18 (Chicago, USA) was used for statistical analysis of study values. All variables were expressed as mean \pm standard deviation (SD). Independent t-test was used to determine the statistical significance of difference in mean between study groups. $p$ values of 0.05 or less were considered statistically significant.

\section{RESULTS}

Study participants were divided into two groups; study group (treated) and control (untreated) (N=60 / group). Study group had a mean age of 32 years compared with 29 years for controls. Both study and control group had a body mass index of $38 \mathrm{~kg} / \mathrm{m}^{2}$ and $36 \mathrm{~kg} / \mathrm{m}^{2}$ respectively. Study group represented pregnant women at their third trimester of pregnancy who did not take iron and folic acid supplements whereas control subject were pregnant women at the same stage but received iron and folic acid supplements (400 $\mu \mathrm{g} /$ day $)$ (Table 1$)$.

Table (1): Basic characteristics of study and control group

\begin{tabular}{cccc}
\hline Parameters & $\begin{array}{c}\text { Study group } \\
\text { (No. = 60) }\end{array}$ & $\begin{array}{c}\text { Controls } \\
\text { (No. = 60) }\end{array}$ & $p$ value \\
\hline Age (years) & $32 \pm 3.61$ & $29 \pm 3.82$ & 0.28 \\
\hline $\begin{array}{c}\text { Body Mass Index } \\
\text { (BMI) } \mathrm{kg} / \mathrm{m}^{2}\end{array}$ & $38.12 \pm 3.14$ & $36.8 \pm 3.42$ & 0.39 \\
\hline $\begin{array}{r}\text { No. and \% of supplement } \\
\text { takers }\end{array}$ & $0(0 \%)$ & $60(100 \%)$ & $\mathrm{NA}$ \\
\hline
\end{tabular}

Among hematological parameters including red blood cell indices, only mean cell volume $(\mathrm{MCV})$ showed a statistically significant difference in study group compared to control ( $p$ $=0.02)$ whereas hemoglobin $(\mathrm{Hb})$, packed cell volume (PCV), red blood cell total count (RBC), mean cell hemoglobin $(\mathrm{MCH})$ and mean cell hemoglobin concentration (MCHC) did not show any significant difference $(p=0.37,0.15$, $0.46,0.41$ and 0.39 ) respectively. However, the biochemical parameter which includes serum iron, was significantly lower in study group compared to controls $(p=0.01)$ (Table 2). 
Table (2): hematological and biochemical parameters among study groups

\begin{tabular}{cccc}
\hline Parameters & $\begin{array}{c}\text { Study group } \\
(\text { No. }=60)\end{array}$ & $\begin{array}{c}\text { Controls } \\
(\text { No. }=60)\end{array}$ & p value \\
\hline $\mathrm{Hb}(\mathrm{g} / \mathrm{dL})$ & $10.9 \pm 3.37$ & $12.3 \pm 2.85$ & 0.37 \\
\hline $\mathrm{PCV}(\%)$ & $33.84 \pm 4.52$ & $39.04 \pm 2.18$ & 0.15 \\
\hline $\mathrm{RBC}(\mathrm{cells} / \mathrm{\mu l})$ & $3.98 \pm 3.12$ & $4.22 \pm 2.77$ & 0.46 \\
\hline $\mathrm{MCV}(\mathrm{fL})$ & $78.53 \pm 5.32$ & $92.51 \pm 4.63$ & 0.02 \\
\hline $\mathrm{MCH}(\mathrm{Pg})$ & $28.14 \pm 5.62$ & $29.12 \pm 6.92$ & 0.41 \\
\hline $\mathrm{MCHC}(\mathrm{g} / \mathrm{dl})$ & $32.92 \pm 3.76$ & $31.53 \pm 3.84$ & 0.39 \\
\hline $\operatorname{lron}(\mathrm{mg} / \mathrm{dL})$ & $69.81 \pm 6.71$ & $82.33 \pm 7.64$ & 0.01 \\
\hline
\end{tabular}

Regarding pulmonary functions test parameters, FEV1, FVC and $\mathrm{O} 2$ saturation \% showed a decrease in study group but were not statistically significant ( $p=0.31,0.98$ and 0.14 ) respectively. However, only FEV1/FVC displayed a statistically significant decline in study group compared to controls (Table 3).

Table (3): pulmonary function test parameters among study groups

\begin{tabular}{cccc}
\hline Parameters & $\begin{array}{c}\text { Study group } \\
(\text { No. }=60)\end{array}$ & $\begin{array}{c}\text { Controls } \\
(\text { No. }=60)\end{array}$ & $p$ value \\
\hline FEV1 (litter) & $2.09 \pm 0.91$ & $2.68 \pm 0.77$ & 0.31 \\
\hline FCV (litter) & $2.31 \pm 1.02$ & 0.98 \\
\hline FEV1/FVC (\%) & $90.47 \pm 0.65$ & $2.98 \pm 0.82$ & 0.001 \\
\hline O2 saturation & & $88.25 \pm 0.32$ & 0.14 \\
\hline
\end{tabular}

Pearson's correlation coefficient was used to determine correlation between variables. We attempted to determine the correlation coefficient in study group between iron and FEV1, FVC and FEV1/FVC respectively. Although there was an obvious positive correlation between FEV1, FVC, FEV1/FVC and serum iron levels, none of them showed a statistically significant correlation $(r=0.238$, 0.493 and 0.969 ) respectively (Table 4). 
Table (4): Pearson's correlation coefficient among variables.

\begin{tabular}{ccc}
\hline Variables & $\boldsymbol{r}$ value & $\boldsymbol{p}$ value \\
\hline FEV1 - Iron & 0.238 & $>0.05$ \\
\hline FVC - Iron & 0.493 & $>0.05$ \\
\hline FEV1/FVC - Iron & 0.656 & $>0.05$ \\
\hline
\end{tabular}

\section{DISCUSSION}

The main goal of this study was to examine the lung functions in third trimester pregnant women and to determine the correlation between pulmonary function parameters and serum iron levels. Despite the fact that, there are conflicting results regarding the changes in the lung functions during pregnancy particularly the third trimester, our results were in concordance with previous studies concluding that there are physiological changes in the lung functions specially FEV1 and FVC during the third trimester of pregnancy. ${ }^{7,8}$ Additionally, there is a high prevalence of anemia in different trimesters of pregnancy particularly the third trimester. ${ }^{9}$

Based on our results, there was an obvious decrease in hematological parameters specifically hemoglobin and packed cell volume in study group compared to controls although they were not statistically significant. Such idea has been confirmed with previous studies indicating that anemia is one of the common nutritional disorders in pregnancy. ${ }^{10}$ Existence of anemia at this stage could have serious complications related to pregnancy outcomes. Studies indicated that the incidence of low birth weight babies was significantly more in mothers who were anemic in their third trimester. Furthermore, preterm deliveries occurred more frequently in mothers who were anemic in their third trimesters. ${ }^{9,11}$ For the reasons above, providing pregnant women with iron supplementations earlier and maintaining hemoglobin within the optimal range, throughout gestation has better pregnancy outcomes regarding premature deliveries and low birth weight babies ${ }^{12}$.

Regarding the reason of decline in lung volumes specifically FEV1 and FVC during the third trimester of pregnancy there are several possible explanations. The enlarged uterus causes upward movement of the diaphragm leading to decrease in negativity of the intra pleural pressure and subsequently a decline in forced vital capacity (FVC). ${ }^{13,14,15} \mathrm{~A}$ decrease in forced expiratory volume in the first second (FEV1) could be due to the decline in the partial pressure of $\mathrm{Co} 2$ ( $\mathrm{Pco} 2$ ) leading in constriction of the respiratory airway passage particularly respiratory bronchioles and alveoli. ${ }^{16,17}$

Another mechanical factor may contribute to decline in lung volumes in general is decrease in the force of expiratory muscle contraction especially anterior abdominal muscles and internal intercostal muscles. ${ }^{18,19}$ Other factors may contribute in addition to the enlarged uterus are weight gain during pregnancy as a result of hormonal changes and edema. ${ }^{20,21}$

The important question which is remained to be answered is the possible mechanism underlying the obvious decrease in lung functions parameters in anemic pregnant women compared to control. Our results are consistent with previous studies indicating that the reduction of FVC, FEV1 and FEV1/ FVC ratio may be attributed to reduction of oxygen carrying capacity of blood resulting in tissue hypoxia and accumulation of intermediary products of metabolism like lactate in the tissue leading to exhaustion which eventually makes the respiratory efforts less powerful ${ }^{22,23}$. In addition; the decrease in the concentration of myoglobin and iron containing enzymes like cytochrome $\mathrm{C}$ in skeletal muscle is roughly proportional to that of hemoglobin in anemia. The resultant decrease in the work capacity due to voluntary respiratory muscles dysfunction could possibly explain the reduction in the force 
or effort dependent parameters like FVC and FEV $1^{24,25}$.

Although the core of the present study was of high scientific value, there are still some possible limitations. Firstly, the sample size was small (60 / group) therefore, future studies should plan for a bigger sample size for better representation of data and to gain a more accurate values. Secondly, the researchers had plans to observe pregnancy outcomes particularly for anemic pregnant women who have had declined lung volumes but this was a quite difficult task due to lack of commitments by study participants. In addition to serum iron measurement in this study, ferritin measurement as well could have been of another strength point for this project.

In conclusion, according to our results, it can be concluded that among changes that occur during pregnancy were declines in lung volumes which may be considered as one of the physiological alterations that taken place during pregnancy. Furthermore, such changes are positively correlated with serum iron levels particularly at the third trimester of pregnancy. This may be due to the fact that low serum iron levels result in weakness of the main respiratory muscles due to tissue hypoxia, accumulation of lactates \& metabolic products, deficiency of myoglobin \& iron containing enzyme cytochrome C. Future research should focus on the pregnancy outcomes after delivery particularly in women who had have iron deficiency anemia with declined lung volumes during the third trimester of pregnancy.

\section{REFERENCES}

World Health Organization. Prevention and management of severe anemia in pregnancy. Report of a Technical Working Group, Geneva, 20-22 May 1993.

Van den Broek NR, Letsky EA. Etiology of anemia in pregnancy in south Malawi. Am J Clin Nutr. 2000;72:247S-56S.

Gomber S, Agarwal KN, Mahajan C, Agarwal N. Impact of daily versus weekly hematianic supplementation on anemia in pregnant women. Indian Pediatr. 2002;39:339-46.

Mcfee JC. Iron metabolism and iron deficiency during pregnancy. Clin Obstet Gynecol. 1997;22:799-808.
Dongmei Sun, Anne McLeod, Shital Gandhi, Ann Kinga Malinowski, Nadine Shehata. Anemia in Pregnancy: A Pragmatic Approach. Obstet Gynecol Surv. 2017; 72(12): 730-737.

Bondevik GT, Lie RT, Ulsteim M, Kvale G. Maternal hematological status and risk of low birth weight and preterm delivery in Nepal. Acta Obstet Gynaecol Scand. 2001;80:402-8.

Neeraj, Sodhi Candy, Pramod J, Singh J, Kaur V. Effect of advanced uncomplicated pregnancy on pulmonary function parameters of North Indian subjects. Indian J. Physiol Pharmacol. $2010: 54$ (1) : 69-72.

Shaikh RM, Deshpande DR, Ganeriwal SK, Reddy BV: Effect of pregnancy on vital capacity and FEV1\%. J Obst Gynecol. 1983; 33 : 495-499.

K Jagadish Kumar, N Asha, D Srinivasa Murthy, MS Sujatha and VG Manjunath. Maternal Anemia in Various Trimesters and its Effect on Newborn Weight and Maturity: An Observational Study. Int J Prev Med. 2013; 4(2): 193-199.

Malik Goonewardene, Mishkat Shehata, Asma Hamad. Anaemia in pregnancy. Best Pract Res Clin Obstet Gynaecol. 2012; 26(1): 3-24.

Steer PJ. Maternal Hemoglobin concentration and birth weight. Am J Clin Nutr. 2000; 71:12857.

Papamatheakis DG, Blood AB, Kim JH, Wilson SM. Antenatal hypoxia and pulmonary vascular function and remodeling. Curr Vasc Pharmacol. 2013;11(5):616-640.

Y.SHAILAJA and S.SRIKANTH. Lung function tests in different trimesters of pregnancy. Indian Journal of Basic and Applied Medical Research. 2013: Vol.-3, Issue-1, P.285-292

Siddiqui AH, Tauheed N, Ahmad A, Mohsin Z. Pulmonary function in advanced uncomplicated singleton and twin pregnancy. J Bras Pneumol. 2014; 40(3):244-249.

Sroczynski T, Gawlikowska-Sroka A, Dzieciolowska-Baran E, PoziomkowskaGesicka I. Causes of respiratory ailments in pregnancy. Eur J Med Res. 2015; 2:189-192. 
Bobrowski RA. Pulmonary physiology in pregnancy. Clin Obstet Gynecol. 2010, 53:285-300.

Girija Priyadarshini. Evaluation of Pulmonary Functions In Third Trimester Pregnant Odia Women and Its Correlation with Severity of Anaemia. IOSR Journal of Dental and Medical Sciences. 2014; (13): 100-104.

Pathak MS, Kurhade G.A., A longitudinal study of antenatal changes in lung function tests and importance of postpartum exerci ses in their recovery. Indian J. Physiol Pharmacol. 2003 : 47 (3) : 352-356.

B. M. Puranik, S. B. Kaore, G. A. Kurhade, S. D. Agrawal, S. A. Patwardhan, J. R. Kher. A longitudinal study of pulmonary function tests during pregnancy. Indian $J$ Physiol Pharmacol. 2014; 38(2): 129-132.

L. Hirnle, L. Lysenko, H. Gerber, P. Lesnik, A. Baranowska, M. Rachwalik, J. Leszczyszyn, L. Strozecki. Respiratory function in pregnant women. Adv Exp Med Biol. 2013; 788: 153160.

Gupta P, Pande J.N, Pulmonary and diaphragmatic functions in chronic severe nutritional anaemia. The National Medical Journal of India. 1989; 2 (6) : $\mathrm{P}-266-268$.

Singhal U, Saxena K. Effect of anaemia on respiratory and metabolic parameters during $3^{\text {rd }}$ trimester of pregnancy. Indian J Physiol Pharmacol. 1987;31(2):130-135.

Dutt SN, Yeshwanth M, Raghuveer TS. Effect of iron deficiency anaemia on pulmonary function in children. Lung India. 1944 ;12(4):168-73.

Dash S, Nanda SS, Behera AK. Pulmonary functions in pregnancy complicated with anemia. Int $J$ Res Med Sci. 2014;2:1431-7.

Ganeriwal SK, Deshpande DR, Reddy BV, Shaikh RM. Effect of pregnancy on pulmonary ventilation. $J$ Obstet Gynecol India. 1984;36:639-41 